\title{
Effect of high energy shot peening on electrochemical corrosion resistance of WE43 magnesium alloy
}

\author{
Gao Wen ${ }^{1, a}$, Wang Shou-ren ${ }^{1, b^{*}}$, Wang Gao-qi ${ }^{1, c}$ and Zhou Ji-xue ${ }^{2, d}$ \\ ${ }^{1}$ School of Mechanical Engineering, University of Jinan, Jinan 250022, China \\ ${ }^{2}$ Institute of New Materials Research, Shandong Academy of Sciences, Jinan 250014, China \\ a E-mail: jxgc_gw@163.com, b E-mail: sherman0158@163.com
}

\begin{abstract}
Keywords. WE43 magnesium alloys; high energy shot peening; grain refinement; Tafel polarization curve

Abstract. In order to study the effect of high energy shot peening on electrochemical corrosion resistance of WE43 magnesium alloy, the electrochemical corrosion behavior in $3.5 \% \mathrm{NaCl}$ solution of WE43 magnesium alloy with different processing duration was investigated. Its crosssectional microstructure, surface 3D morphology and microhardness were also examined and analyzed. The experimental results showed that the electrochemical corrosion resistance of WE43 magnesium alloy was improved after high energy shot peening. A certain thickness of plastic deformation layer was produced after treated. With the increasing of treated time, the selfcorrossion potential of WE43 began to move towards a positive direction, the corrosion current density decreased.
\end{abstract}

\section{Introduction}

Magnesium and magnesium alloys are widely used in the field of aerospace, electronic communications, military equipment and others fields with their superior performance of its rich resources, low price, low density, high specific strength and stiffness and so on. However, the fatal weaknesses of magnesium and magnesium alloys, which is the poor mechanical properties and corrosion resistance, have greatly limited their deeper application in all fields. Therefore, the key to develop the application of magnesium alloys is to improve the corrosion resistance of magnesium and magnesium alloys.

A number of techniques have been developed to modify the service behavior of magnesium alloys through surface treatment. For example, electroplating ${ }^{[1]}$, chemical conversion treatment, anodic oxidation treatment, laser surface alloying and micro arc oxidation, and so on ${ }^{[2]}$. But these methods have certain inevitable disadvantage of involving multilayer coatings or expensive. It is pointed out that the grain size of magnesium alloys has a great influence on their corrosion resistance, which could be improved significantly through grain refinement ${ }^{[3]}$. High energy shot peening is the typical representative method for making a severe plastic deformation in the surface layer ${ }^{[4]}$. The change of high cycle fatigue property of TC11 titanium alloy after shot peening was studied by YAN Zhen ${ }^{[5]}$, he found that the maximum fatigue strength of shot peenned treated samples are increased by $37 \%$. The fatigue performance of corrosion damage components of aluminum alloy demonstrated significantly enhancement if the components were shot peened before decomposed $^{[6]}$. However, current researches for shot peening strengthening are focus on the effect of shot peening on fatigue resistance and physical properties of metal materials, and are also mainly concentrated in the corrosion resistance of carbon steel and alloy steel. The study of shot peening on magnesium alloys corrosion resistance is rarely reported.

In order to improve the the corrosion resitance of magnesium alloys, the purpose of this paper is to investigate the effect on electrochemical corrosion resistance of WE43 magnesium alloy induced by high energy peening.

\section{Experimental procedures}

The material used in this study was a rare earth magnesium alloy (Mg-4\% $-3.3 \% \mathrm{RE}(\mathrm{Nd}, \mathrm{Gd})$ $0.5 \% \mathrm{Zr}$ ) with size of $10 \mathrm{~mm} \times 10 \mathrm{~mm} \times 5 \mathrm{~mm}$. The samples was devided into 5 groups according to 
different processing duration, which treated time is $0,60 \mathrm{~s}, 90 \mathrm{~s}, 120 \mathrm{~s}$ and $240 \mathrm{~s}$ respectively. The surface of samples should be polished orderly with 400 grit to 1000 grit sandpapers. The schematic shot peening process of high energy shot penning equipment and the strengthening mechanism were shown in Figure 1. And the main parameters of high energy peening process were chosen as follows: the diameter of steel peening shoots was about $0.8 \mathrm{~mm}$, and the pressure of gases was $0.45 \mathrm{MPa}$; the bombarding distance was $300 \mathrm{~mm}$, the shoot angle was about $90^{\circ}$.

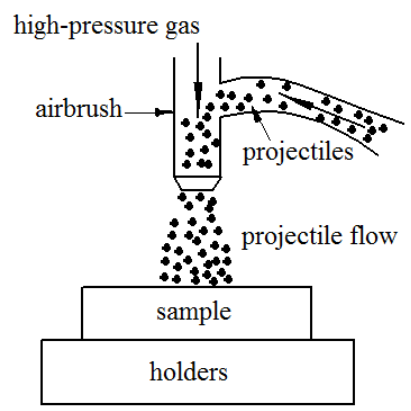

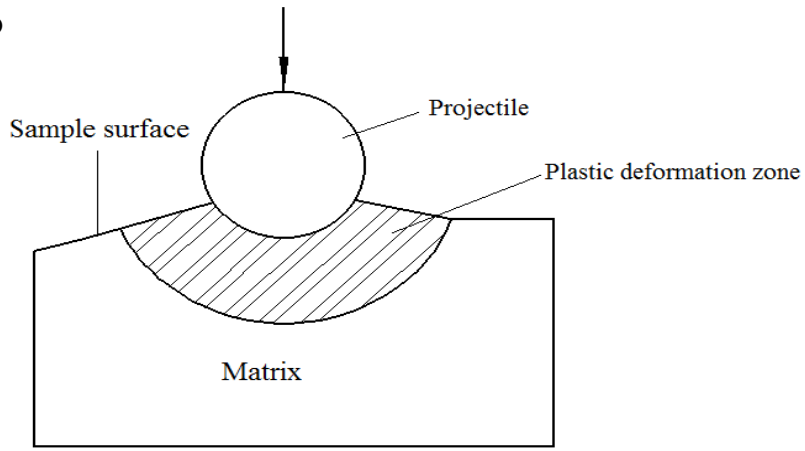

Figure 1. Schematic diagram of high energy peening : (a) schematic shot peening process diagram; (b) strengthening mechanism

Tafel polarization curve test was done using Shanghai Chen Hua CHI604E electrochemical workstation. Classic three electrode system was used in the experiment, which the sample electrode, reference electrode and auxiliary electrode were tested samples (work area was $1 \mathrm{~cm}^{2}$ ), saturated calomel electrode and platinum electrode, respectively. The test was carried out at room temperature in $3.5 \% \mathrm{NaCl}$ solution. The potential scan range of is $-1.8 \mathrm{~V} \sim-1.0 \mathrm{~V}$, and the scanning rate is $1 \mathrm{mv} / \mathrm{s}$. The schematic diagram of electrochemical workstation was shown in Figure 2.

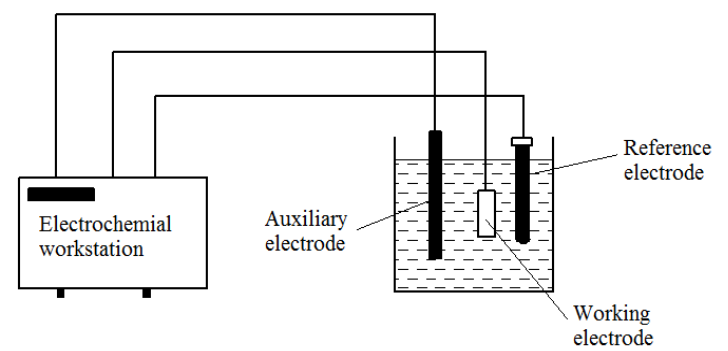

Figure 2. Schematic diagram of electrochemical workstation

Samples were ultrasonic cleaned in ethanol for 10min in order to remove contaminants from the shot-peening process. An VH-Z500R ultra deep microscopy was used to examine the microstructural change along sections perpendicular to the treated surface and surface 3D morphology. The surface microhardness was determined by a micro-hardness tester with a loading time of 5s. Before cross-sectional microstructure observation, the corresponding surface polishing was needed. The samples was roughly grounded by 400\#, 800\#, 1200\# and 1500\# sandpapers and then polished by electrolytic polishing instrument at $-25^{\circ} \mathrm{C}$. The main paramaters for electrochemical polishing were chosen as Table 1. Finally, the polished samples were corroded by picric acid for $3 \mathrm{~s} \sim 5 \mathrm{~s}$.

Table 1. Paramaters for electrochemical polishing

\begin{tabular}{|c|c|}
\hline Parameters & contents \\
\hline Electrolyte & Perchloric acid and alcohol(1:9) \\
\hline Voltage & $10(\mathrm{~V})$ \\
\hline Electrolysis time & $45 \sim 60(\mathrm{~s})$ \\
\hline Anode electrode & Samples \\
\hline Cathode electrode & Stainless steel plate \\
\hline
\end{tabular}




\section{Results and discussion}

\subsection{Analysis of microstructure, 3D morphology and microhardness}

The cross-sectional microstructures are presented in Figure 3. The cross-sectional microstructures of all treated samples are basically same, then, the following representative picture was chosen to illustrate the effect of high energy shot peening on microstructure. It can be seen that the microstructure morphology of the deformed layer differs obviously from that in the substrate, which microstructure morphology present chain of grains among large grains. The thickness of distinct deformed layer is about $220 \mu \mathrm{m}$, a nanocrystalline zone microstructure, which is beyond the resolution of microscope in the top layer, is about $120 \mu \mathrm{m}$. And, a large number of deformation twins are found in the depth about $120 \mu \mathrm{m} 220 \mu \mathrm{m}$ from top surface. In brief, the microstructures change gradually from the substrate to the top surface.

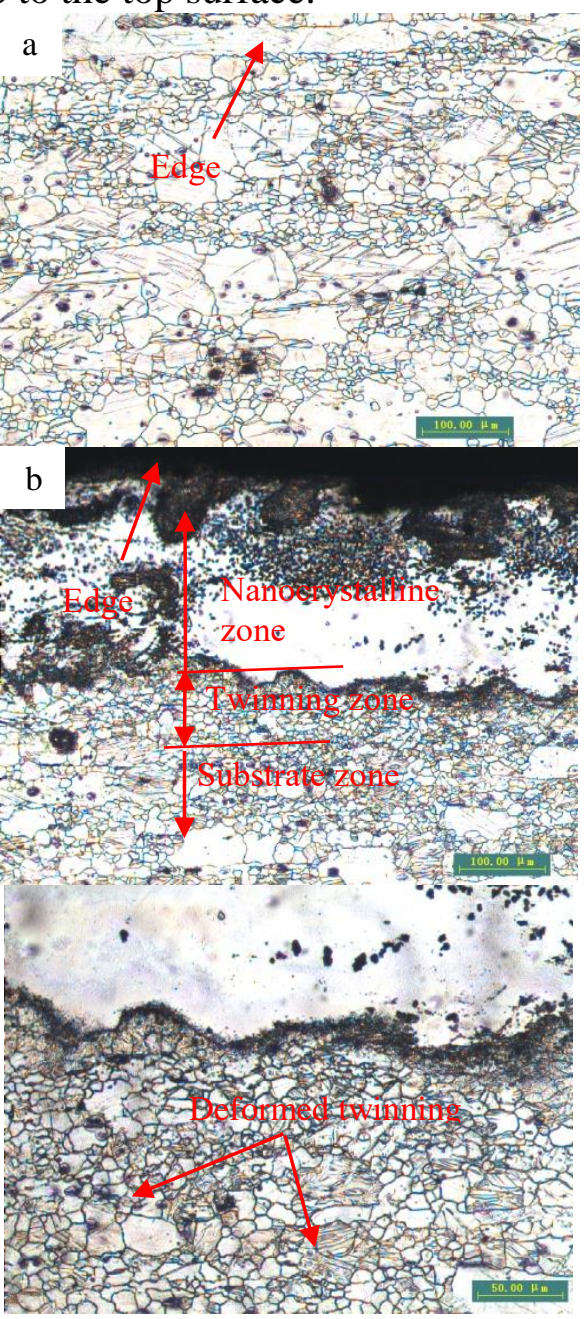

Figure 3. Cross-sectional microstructure observation in:(a)Untreated;(b)Shot-peening treated;(c) magnify the picture(b) to 200 times

Deformed twinning on the surface of WE43 magnesium alloy samples induced through severe plastic deformation, which caused by a large number of high-speed particles impact the material surface during a short period of time. The higher the twinning density is, the more the dislocation increase. And, large grains will be broken, making grain refinement ${ }^{[7]}$. According to the micro strain size, grain shape and size, the treated samples can be devided into three zones along the direction of thickness, these zones can be named nanocrystalline layer, ultrafine crystal layer and original grain layer ${ }^{[8]}$.

Figure 4 shows the 3D morphology of samples after high energy shot peening. It shows that the surface roughness of treated samples (the peak-to-valley value of samples which treated time is $60 \mathrm{~s}, 90 \mathrm{~s}, 120 \mathrm{~s}$ and $240 \mathrm{~s}$ are $106.3,99.06,84.32$ and 92.96 respectively) is obviously more higher 
compared to untreated samples(the peak-to-valley value of samples is just 13.49). The surface morphology of treated samples, which is the result of the severe plastic deformation, are irregular and rugged valley shaped. And, the surface appearance for processing duration of $120 \mathrm{~s}$ is the most ideal of all treated conditions.

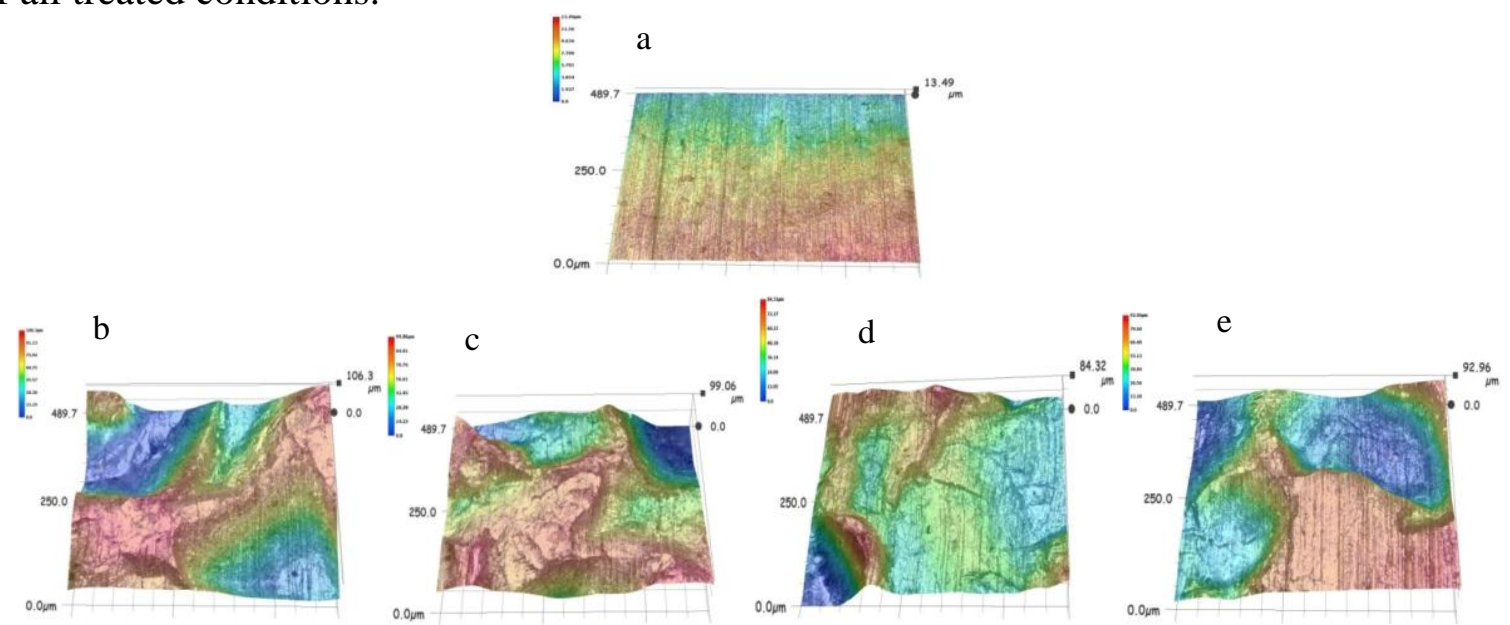

Figure 4. 3D morphology of samples: (a) Untreated; (b) Treated in 60s; (c) Treated in 90s: (d) Treated in 120s; (e) Treated in $240 \mathrm{~s}$

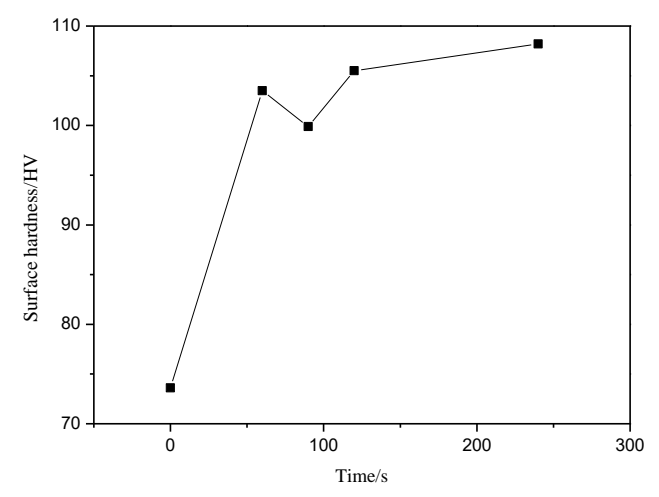

Figure 5.Surface microhardness of shot peening

Figure 5 shows the microhardness of the treated samples surface. As we can see, the microhardness of the material surface, which the value reaches a maximum about $108 \mathrm{HV}$ with treated time for $240 \mathrm{~s}$, is significantly increased by the shot peening treatment. The microhardness of the surface layer is increased by forty-three percent in comparison with that of the substrate (the value of microhardness is about $73 \mathrm{HV}$ ). These results indicate that the increase of microhardness from the substrate to the surface is caused by the grain refinement.

\subsection{Electrochemical analysis}

Tafel polarization curves of WE43 magnesium alloy in 3.5\% $\mathrm{NaCl}$ solution is shown in Figure 6. Table 2 listed self corrosion potential and corrosion current density obtained from the Tafel polarization curves. As we can see, high energy shot penning results in a superior corrosion resistance compared to untreated samples. In all cases, the corrosion potential of treated samples move positive substantially. Further, samples shot peened for $60 \mathrm{~s}, 90 \mathrm{~s}, 120 \mathrm{~s}$ and $240 \mathrm{~s}$ have a positive shift of $141 \mathrm{mV}, 153 \mathrm{mV}, 203 \mathrm{mV}$ and $166 \mathrm{mV}$, respectively. And, the corrosion current density of shot peened WE43 magnesium alloys were reduced by $16.8 \%, 30.29 \%, 31.25 \%$ and $24.52 \%$. Moreover, the case of shot peened for $120 \mathrm{~s}$, which self corrosion potential and corrosion current density is $-1.211 \mathrm{~V}$ and $1.43 \times 10^{-4} \mathrm{~A} \cdot \mathrm{cm}^{-1}$ respectively, is the most ideal condition compared others cases. When the processing duration is 240 s, the corrosion resistance of WE43 magnesium alloys is no longer improved continuely. 
Table 2. Tafel paramaters of WE43 magnesium alloy

\begin{tabular}{|c|c|c|c|c|c|}
\hline Time & 0 & $60 \mathrm{~s}$ & $90 \mathrm{~s}$ & $120 \mathrm{~s}$ & $240 \mathrm{~s}$ \\
\hline$E_{\mathrm{corr}} / \mathrm{V}$ & -1.414 & -1.273 & -1.261 & -1.211 & -1.248 \\
\hline$I_{\mathrm{corr}} / \mathrm{A} \cdot \mathrm{cm}^{-1}$ & $2.08 \times 10^{-4}$ & $1.73 \times 10^{-4}$ & $1.45 \times 10^{-4}$ & $1.43 \times 10^{-4}$ & $1.57 \times 10^{-4}$ \\
\hline
\end{tabular}

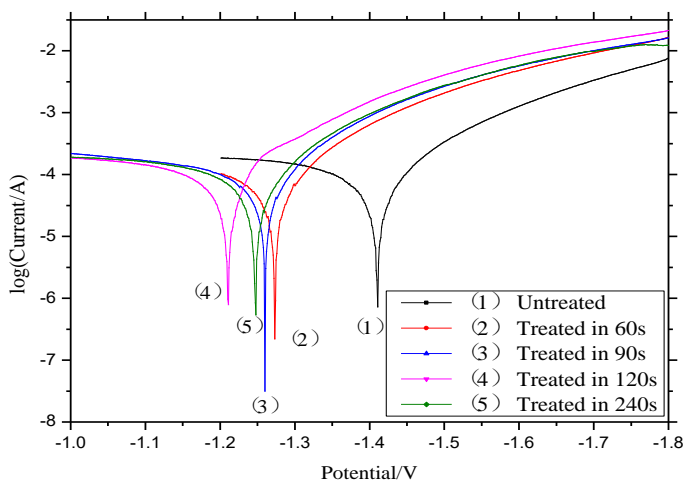

Figure 6. Tafel polarization curves of WE43 magnesium alloy in $3.5 \% \mathrm{NaCl}$ solution

Because of the natural activity of magnesium alloys, a $\mathrm{Mg}(\mathrm{OH})_{2}$ film, which can protect magnesium alloys substrate from destruction, will be generated naturally on the material surface. And, the corrosion resistance of the film depends on the properties of the passive film. Therefore, the corrosion process of magnesium alloys is a continuous destruction and repair of passive film ${ }^{[9]}$. The reaction of magnesium alloy in neutral solution is as follows:

$$
\begin{aligned}
& \mathrm{Mg}=\mathrm{Mg}^{2+}+2 \mathrm{e}^{-} \\
& 2 \mathrm{H}_{2} \mathrm{O}+2 \mathrm{e}^{-}=\mathrm{H}_{2}+2 \mathrm{OH}^{-} \\
& \mathrm{Mg}^{2+}+2 \mathrm{OH}^{-}=\mathrm{Mg}(\mathrm{OH})_{2}
\end{aligned}
$$

However, the $\mathrm{Mg}(\mathrm{OH})_{2}$ passive film on the magnesium alloy surface is prone to be destroyed with pitting corrosion while the environment contains $\mathrm{Cl}^{-1[10]}$. This destruction results from the generation of tensile stress along with the formation of oxide film on the surface of magnesium alloys $^{[11]}$. And, the growth of the film accompanied by the increase of tensile stress results in the acceleration of corrosion. The grain of WE43 magnesium alloy is refined by high energy shot peening, and the residual compressive stress is produced. The compressive stress and the density of the passive film will be increased because of residual compressive stress, leading the inhibition of the destruction of passive film. Moreover, residual compressive stress also have positive impact on the surface crack initiation and propagation, reducing corrosion rate ${ }^{[12]}$.

\section{Conclusions}

Cross-sectional microstructure, surface 3D morphology, microhardness and electrochemical properties of a WE43 magnesium alloys nanocrystalline surface layer prepared by high energy shot peening treatment were investigated, in comparison with untreated samples.

(1) Cross-sectional microstructure shows that the microstructure changes gradually from the substrate to the surface. The grain refinement was obviously and the grain size increases gradually from the top surface to substrate. And, the surface roughness and microhardness at the top surface layer was improved obviously. 
(2) From the Tafel polarization curves, the corrosion potential of treated samples move positive substantially, and the corrosion current density of shot peened WE43 magnesium alloys were all reduced.

(3) These results indicated that high energy shot penning results in a superior corrosion resistance compared to untreated samples.

\section{Acknowledgments}

This work is supported by the National Natural Science Foundation of P.R. China (ID: 51372101) and Taishan scholar engineering special funding References.

\section{References}

[1] U. Erb, A.M. El-Sherik, G. Palumbo, K.T. Aust, Nanostruct. M. 2 (1993) 383 390.

[2] C.B Wei, C.CZhang, X.B Tian,etc. Surface Modification Techniques to Improve CorrosionResistance of Magnesium Alloys, 32(2004) 6 11.

[3] G.L SONG, S.J David. The effcct of zirconium grain refinement on the corrosion behavior of magnesium-rare earth alloy MEZ. J of LM, 2(2002) 1 16.

[4] W.J Xue, L.S Liu, K.Y Wang,etc. Application and Development Trend of Shot Peening Treatment Technologies. M P, 05(2014)46-49.

[5] Z Yan, Y.L Liang, Z.J Zhang, J Xu, Y.L Yi. High Cycle Fatigue Behavior of TC11 Titanium Alloy by Shot Peening Strengthening. CJ ofRM, 04(2014)554-560.

[6] H.H Deng, Q.X Xia, X.Q Cheng, Y.P REN. Effects on Anti-corrosion Fatigue Property of Aluminum Alloy after Shot Peening. ST, 01(2016)118-123.

[7] K.D Xu, J.N Wang, A.H Wang.Surface nanocrystallization and its properties of a rare earth magnesium alloyinduced by HVO-SMB.11(2011)677 681

[8] M Sun.Study on grain refinement behavior of Mg-Gd-Y.Shanghai Jiao Tong University, 2012.

[9] G Yu, Y.L Liu, Y Li, L.Y Ye, X.H Guo, L Zhao . Corrosion and protection of magnesium alloys, TCJofNM. 06(2002)1087-1098.

[10]F.H Wang, K.Q Du, W Zhang. Progress in research of Corrosion and protection of magnesium alloys.MC.02(2011) 29-34.

[11]C.N Cao. Principle of corrosion electrochemistry. CS and PT, 03(2008)165.

[12] Y SANO, M OBATA, T KUBO.Retardation of crack initiation and growth in austenitic stainless steels by laser peening without protective coating. MS and E, 417(2006), 334-340. 